\title{
How many prehospital defibrillation attempts should be performed in out-of-hospital cardiac arrest patients with shockable rhythm?
}

\section{Byuk Sung Ko}

Hanyang University College of Medicine

\section{Youn-Jung Kim}

University of Ulsan College of Medicine

\section{Kap Su Han}

Korea University College of Medicine and School of Medicine

\section{You Hwan Jo}

Seoul National University Bundang Hospital

\section{Jonghwan Shin}

Seoul Metropolitan Boramae Hospital: Seoul National University Seoul Metropolitan Government Boramae Medical Center

\section{Incheol Park}

Yonsei University College of Medicine

\section{Hyunggoo Kang}

Hanyang University College of Medicine

Tae Ho Lim

Hanyang University College of Medicine

\section{Sung Oh Hwang}

Yonsei University Wonju College of Medicine

Won Young Kim ( $\nabla$ wonpia73@naver.com )

Department of Emergency Medicine, University of Ulsan College of Medicine, Asan Medical Center https://orcid.org/0000-0002-6904-5966

\section{Research}

Keywords: cardiac arrest, out of hospital, return of spontaneous circulation, defibrillation, pre hospital

Posted Date: November 13th, 2020

DOI: https://doi.org/10.21203/rs.3.rs-106512/v1 
License: (c) (i) This work is licensed under a Creative Commons Attribution 4.0 International License. Read Full License 


\section{Abstract}

Background: Early defibrillation is vital to improve outcomes after out-of-hospital cardiac arrest (OHCA) with shockable rhythm. Currently, there is no agreed consensus on the number of defibrillation attempts before transfer to a hospital. This study aimed to evaluate the correlation between the number of defibrillations on the prehospital return of spontaneous circulation (ROSC).

Methods: A multicenter, prospective, observational registry-based study was conducted for OHCA in patients with presumed cardiac etiology that underwent prehospital defibrillation between October 2015 and June 2017. The primary outcome was prehospital ROSC, and the secondary outcome was a good neurologic outcome at hospital discharge, defined as Cerebral Performance Category score 1 or 2.

Results: Among 2,155 OHCA patients' data, 178 patients with missing data were excluded, a total of 1,983 OHCA patients who received prehospital defibrillation were included. The median age was 61 years and prehospital ROSC was observed in 738 patients (37.2\%). The median time from arrest to first defibrillation was 10 (interquartile range: 7-15) minutes. The cumulative ROSC rates and good neurologic outcome from the initial defibrillation to the sixth defibrillation were $43 \%, 68 \%, 81 \%, 90 \%, 95 \%, 98 \%$ and $42 \%, 66 \%, 81 \%, 90 \%, 95 \%, 98 \%$, respectively. After clinical characteristics adjustment and time to defibrillation, the number of defibrillations were independently associated with ROSC (odds ratio 0.81 $95 \% \mathrm{Cl}$ 0.76-0.86) and good neurologic outcome (odds ratio $0.8695 \% \mathrm{Cl}$ 0.80-0.91). Moreover, subgroup analysis results with patients that underwent the initial defibrillation within 10 minutes from arrest were consistent (95\% up to five times).

Conclusion: More than 95\% of prehospital ROSC was achieved within five times of defibrillation in OHCA patients. This result provides a basis for the ideal number of defibrillation attempts before transfer to hospital with the possibility of extracorporeal cardiopulmonary resuscitation in these refractory ventricular fibrillation patients.

\section{Introduction}

With advances in cardiac arrest resuscitation, the rate of survival discharge in patients with out-ofhospital cardiac arrest (OHCA) who receive cardiopulmonary resuscitation (CPR) have been reported ranging from 7.5-10.8\% [1-4]. The first monitored rhythm is ventricular fibrillation (VF) and pulseless ventricular tachycardia (pVT) in approximately $20 \%$ of cardiac arrests, but the incidence of VF/pVT can vary according to bystander CPR rates [5-8]. VF/pVT will also occur at some stage during resuscitation in about $25 \%$ of cardiac arrests with an initial documented rhythm of asystole or pulseless electrical activity [9].

Early defibrillation, one of the chain of survival, plays an important role in improving cardiac arrest patients' survival from VF/Pvt [10]. During treatment of VF/pVT, with every minute that passes between collapse and defibrillation, survival rates decrease by $7-10 \%$ if no CPR is provided, and $3-4 \%$ if bystander CPR is provided $[11,12]$. Guidelines for CPR have recommended a single-shock strategy 
without escalating the shock energy, without delay. If ROSC has not been achieved by the third shock, the adrenaline may increase the chance of successful defibrillation with the next shock. However, the optimal number of prehospital defibrillation attempts in OHCA patients with VF/pVT before transfer to the hospital is unknown. Since repetitive defibrillation is required to treat VF refractory to defibrillation, knowledge of the effective number of defibrillations is important in the initial treatment process for VF. As recurrence of VF after first defibrillation is common, two or more defibrillations are typically necessary [13]. One study reported that $48 \%$ of the cohort presented with refibrillation within two minutes of the first defibrillation shock, and $74 \%$ received at least one shock for refibrillation during prehospital care [13]. Patients with refractory VF can be candidates for rescue treatments such as extracorporeal CPR if they arrive at the hospital within a reasonable time.

This study aimed to investigate defibrillation success rates based on the number of defibrillation attempts on OHCA patients that received prehospital defibrillation.

\section{Material And Methods}

\section{Study population}

This retrospective review of multicenter, prospective, observational registry was conducted between October 2015 and June 2017, using data from the Korean Cardiac Arrest Research Consortium (KoCARC). KoCARC is a multi-institutional, nationwide collaborative research network of 62 participating institutions developed to investigate the various studies conducted in the field of OHCA and to enhance collaborative efforts to carry out the studies.[14] The KoCARC registry was designed to include OHCA patients that had been transported to the participating emergency departments (ED) by emergency medical services (EMS) with resuscitation efforts and patients who had a medical etiology identified by an emergency physician.

The registry excluded OHCA patients with terminal illness documented by medical records, hospice care, pregnancy, and pre-documented "No Resuscitation" cards. Also excluded were those with clear nonmedical etiology including trauma, drowning, poisoning, burns, asphyxiation, or hanging. The quality control committee's quality assurance plan includes integrity checks for required fields, and built-in validation rule cross-checks for data fields. They also provide feedback to research coordinators and investigators regarding quality control processes through quarterly meetings. The KoCARC data collection protocol was reviewed and approved by the Institutional Review Board of each participating hospital. The KoCARC Registry was registered at Clinicaltrials.gov (Identifier NCT03222999). A detailed description of the registry has been presented elsewhere $[14,15]$.

\section{Study Design And Data Variables}

In addition to the general registry described above, this study used a specific design. Our study only included OHCA in patients with presumed cardiac etiology who underwent prehospital defibrillation. Cardiac etiology was defined as a case of receiving defibrillation treatment at least once. The patients without information on defibrillation were excluded. We also excluded patients without information on outcome. 
Patient characteristics (age, gender), prehospital characteristics (prehospital initial rhythm, bystander CPR, witnessed by a bystander, automated external defibrillator use and defibrillation). Drug administration by EMS personnel, prehospital advanced airway, prehospital ROSC (defined as the restoration of a palpable pulse $\geq 20$ minutes), time interval (arrest time to initial defibrillation, response time defined as time from EMS call to scene arrival, scene time defined as the time from scene arrival to scene departure, and transport time defined as the time from scene departure to hospital arrival), and hospital outcomes from the KoCARC registry.

The defibrillation strategies for VF/pVT in South Korea follow the current guidelines for CPR, including single shock and not escalating energy dose for subsequent shocks. However, the duration of field resuscitation and defibrillation attempts are varied by their medical directors [16]. EMS personnel were unable to abandon on-site resuscitation attempts unless OHCA patients showed obvious signs of death. Overt signs of death are defined as the presence of (1) head-body disconnection, (2) rot, or (3) postmortem rigidity. Therefore, all EMS-treated OHCA patients should be transferred to the ED.

The success of prehospital defibrillation was defined as the achievement of ROSC. The primary outcome of this study was prehospital ROSC rates. The secondary outcome was a good neurologic outcome at the point of hospital discharge, and was defined as a Cerebral Performance Category (CPC) score of 1 (good cerebral performance) and 2 (moderate cerebral disability) [17]. Multivariable logistic regression analysis was used to confirm whether the number of defibrillations were independently associated with outcomes after adjusting for clinical characteristics and time to initial defibrillation.

\section{Statistical analysis}

Continuous variables were analyzed as mean \pm standard deviation or median of the interquartile range (IQR), and categorical variables were analyzed as absolute or relative frequency. Student's t-test or MannWhitney u-test were used to compare continuous variables, and categorical variables were chi-square test or Fisher's exact test.

The baseline characteristics of the whole study population were analyzed. Multivariable logistic regression analysis was used to determine the predictors for prehospital ROSC and good neurologic outcome. Potential confounding factors that were adjusted for in the multivariable analyses included sex, age, prehospital initial rhythm, bystander CPR, witnessed by a bystander, number of defibrillation attempts, drug administration by EMS personnel, prehospital advanced airway and time interval (arrest time, response time, scene time and transport time).

Cumulative incidence of prehospital ROSC and good neurologic outcome according to the number of defibrillations were examined. Subgroup analysis of patients who underwent defibrillation within the median time from arrest first defibrillation was also assessed to minimize the effect of late defibrillation on the outcome. 
All statistical analyses were performed using the SPSS statistical package, version 24 (IBM). All tests were two-tailed, and $\mathrm{P}$ values of less than 0.05 were considered statistically significance.

\section{Results}

\section{Participant characteristics}

During the study period, 2,155 patients with OHCA presumed cardiac etiology who received prehospital defibrillation were included. Among them, 165 patients were excluded due to lack of defibrillation information. A further 13 patients were excluded due a lack of outcome information (six patients were also missing defibrillation information). Finally, a total of 1,983 patients were included in the study and used for analysis.

The median age of the whole population was 61 years, and the majority were male 1,553 (78.3\%) (Table 1). In the prehospital stage, 738 patients underwent ROSC (37.2\%). The median age was significantly lower in the group of patients with prehospital ROSC than those who were without. The proportion of males were significantly higher in the group with ROSC. The proportion of initial shockable rhythm, witnessed cardiac arrest, and bystander CPR were significantly higher in the group with ROSC than those without ROSC. The median number of prehospital defibrillations was 2 (IQR: 1-4). The median time from arrest to initial defibrillation was 10 minutes (IQR: 7-15). The survival rate at hospital discharge was $33.2 \%$, and the proportion of good neurological outcome was $27.7 \%$. Other characteristics were summarized in Table 1. 
Table 1

Demographic and Prehospital Characteristics of Study Population

\begin{tabular}{|c|c|c|c|c|}
\hline Variables & Total & $\begin{array}{l}\text { Prehospital } \\
\text { ROSC (+) }\end{array}$ & $\begin{array}{l}\text { Prehospital } \\
\text { ROSC }(-)\end{array}$ & $\begin{array}{l}p \\
\text { value }\end{array}$ \\
\hline & $\begin{array}{l}(\mathrm{N}= \\
1,983)\end{array}$ & $(n=738,37.2 \%)$ & $\begin{array}{l}(n=1245 \\
62.8 \%)\end{array}$ & \\
\hline Age, years, median (IQR), y & $\begin{array}{l}61(61- \\
72)\end{array}$ & $57(48-57)$ & $65(53-75)$ & $<.001$ \\
\hline Male, n (\%) & $\begin{array}{l}1553 \\
(78.3 \%)\end{array}$ & $598(81 \%)$ & $955(76.7 \%)$ & 0.024 \\
\hline \multicolumn{5}{|l|}{ History, n (\%) } \\
\hline Hypertension & $\begin{array}{l}725 \\
(36.6 \%)\end{array}$ & $264(39.9 \%)$ & $461(45.9 \%)$ & 0.015 \\
\hline Diabetes mellitus & $\begin{array}{l}400 \\
(20.2 \%)\end{array}$ & $132(20.2 \%)$ & $268(26.8 \%)$ & 0.003 \\
\hline Dyslipidemia & $\begin{array}{l}102 \\
(6.5 \%)\end{array}$ & $52(8.3 \%)$ & $50(5.3 \%)$ & 0.021 \\
\hline Initial shockable rhythm, n (\%) & $\begin{array}{l}1535 \\
(77.4 \%)\end{array}$ & $654(91.2 \%)$ & $881(72 \%)$ & $\begin{array}{l}< \\
0.001\end{array}$ \\
\hline Witnessed by bystander, $\mathrm{n}(\%)$ & $\begin{array}{l}1459 \\
(73.6 \%)\end{array}$ & $596(82.7 \%)$ & $863(69.8 \%)$ & $<0.001$ \\
\hline Bystander CPR, n (\%) & $\begin{array}{l}1210 \\
(61 \%)\end{array}$ & $486(70.3 \%)$ & $724(61.3 \%)$ & $\begin{array}{l}< \\
0.001\end{array}$ \\
\hline Defibrillation number, median (IQR) & $2(1-4)$ & $2(1-3)$ & $2(1-4)$ & $\begin{array}{l}< \\
0.001\end{array}$ \\
\hline $\begin{array}{l}\text { Drug administration by EMS personnel, } n \\
(\%)\end{array}$ & $\begin{array}{l}351 \\
(17.7 \%)\end{array}$ & $84(11.9 \%)$ & $267(22 \%)$ & $<0.001$ \\
\hline Prehospital advanced airway, n (\%) & $\begin{array}{l}141 \\
(7.1 \%)\end{array}$ & $47(6.4 \%)$ & $94(7.6 \%)$ & 0.366 \\
\hline \multicolumn{5}{|l|}{ Time variables } \\
\hline $\begin{array}{l}\text { Arrest time to } 1 \text { st defibrillation, median } \\
(\text { IQR), minutes }\end{array}$ & $\begin{array}{l}10(7- \\
15)\end{array}$ & $9(7-13)$ & $11(8-17)$ & $<0.001$ \\
\hline Response time, median (IQR), minutes & $7(5-9)$ & $7(5-9)$ & $7(5-10)$ & $<0.001$ \\
\hline Scene time, median (IQR), minutes & $\begin{array}{l}12(9- \\
18)\end{array}$ & $11(8-15)$ & $14(9-20)$ & $<.001$ \\
\hline
\end{tabular}

$\mathrm{CPR}$ = cardiopulmonary resuscitation; EMS = emergency medical services; IQR = interquartile range; $\mathrm{ROSC}=$ return of spontaneous circulation 


\begin{tabular}{|lllll|}
\hline Variables & Total & $\begin{array}{l}\text { Prehospital } \\
\text { ROSC (+) }\end{array}$ & $\begin{array}{l}\text { Prehospital } \\
\text { ROSC (-) }\end{array}$ & $\begin{array}{l}\boldsymbol{p} \\
\text { value }\end{array}$ \\
\hline Transport time, median (IQR), minutes & $9(6-14)$ & $11(7-16)$ & $9(6-12)$ & $<$ \\
\hline Outcomes & & & & \\
\hline Survival at hospital discharge, $\mathrm{n}(\%)$ & $\begin{array}{l}659 \\
(33.2 \%)\end{array}$ & $528(86.7 \%)$ & $131(37.6 \%)$ & $<$ \\
\hline $\begin{array}{l}\text { Good neurologic outcome at hospital } \\
\text { discharge, } \mathrm{n}(\%)\end{array}$ & $\begin{array}{l}549 \\
(27.7 \%)\end{array}$ & $478(64.8 \%)$ & $71(5.7 \%)$ & 0.001 \\
\hline $\begin{array}{l}\text { CPR = cardiopulmonary resuscitation; EMS = emergency medical services; IQR = interquartile range; } \\
\text { ROSC = return of spontaneous circulation }\end{array}$ & & & \\
\hline
\end{tabular}

\section{Outcomes According To The Numbers Of Defibrillation}

ROSC rates decreased as the number of defibrillation attempts at the prehospital stage increased from the first to the sixth. $16 \%, 11 \%, 7 \%, 5 \%, 3 \%$ and $1 \%$, respectively (Additional Fig). The cumulative ROSC rates and good neurologic outcome from the first to sixth defibrillation were $43 \%, 68 \%, 81 \%, 90 \%, 95 \%$, $98 \%$ and $42 \%, 66 \%, 81 \%, 90 \%, 95 \%, 98 \%$, respectively (Fig. 1). A total of $704(95 \%)$ patients showed ROSC with less five defibrillations. Less than five defibrillations were also associated with $95 \%$ of good neurologic outcomes. As the time from arrest to first defibrillation affects the patient's outcome, a subgroup analysis was performed on patients who received defibrillation within 10 minutes which was the median first defibrillation time. There were 888 patients $(44.7 \%)$ that had received their first defibrillation within 10 minutes. Similar to the main analysis, it was shown that $95 \%$ patients exhibited ROSC with less than five defibrillations (Fig. 2). A subgroup analysis was performed on patients whose first defibrillation time exceeded 10 minutes from cardiac arrest. Similar to the main analysis, the cumulative ROSC rate in patients who underwent defibrillation up to five times was $96 \%$ (Fig. 3).

\section{Analysis To Find Predictors For Prehospital Defibrillation Success}

Univariate and multivariable analyses were conducted to find predictors related to prehospital ROSC. Age was significantly associated with reduced prehospital ROSC using univariate analysis (odds ratio [OR]: 0.972 , Cl [confidence interval]: 0.966-0.978) (Table 2). The initial shockable rhythm, witnessed arrest and bystander CPR were significantly associated with prehospital ROSC (OR: 4.042, 2.061 and 1.496, respectively). Increasing numbers of defibrillation attempts were significantly associated with reduced prehospital ROSC (OR: 0.856, Cl: 0.816-0.899, p<0.001). 
Table 2

Univariate Regression Analysis and Multivariable Logistic Regression Analysis for Predicting Prehospital return of spontaneous circulation

\begin{tabular}{|c|c|c|c|c|}
\hline \multirow[t]{2}{*}{ Variables } & \multicolumn{2}{|c|}{$\begin{array}{l}\text { Univariate } \\
\text { regression analysis }\end{array}$} & \multicolumn{2}{|c|}{$\begin{array}{l}\text { Multivariable } \\
\text { regression analysis }\end{array}$} \\
\hline & OR $(95 \% \mathrm{Cl})$ & $\begin{array}{l}p \\
\text { value }\end{array}$ & OR $(95 \% \mathrm{Cl})$ & $\begin{array}{l}p \\
\text { value }\end{array}$ \\
\hline Age, median, y & $\begin{array}{l}0.972(0.966- \\
0.978)\end{array}$ & $<.001$ & $\begin{array}{l}0.971(0.946- \\
0.979)\end{array}$ & $<.001$ \\
\hline Male & $\begin{array}{l}1.297(1.035- \\
1.626)\end{array}$ & 0.024 & & \\
\hline \multicolumn{5}{|l|}{ History } \\
\hline Hypertension & $\begin{array}{l}0.781(0.64- \\
0.953)\end{array}$ & 0.015 & & \\
\hline Diabetes mellitus & $\begin{array}{l}0.692(0.546- \\
0.877)\end{array}$ & 0.002 & & \\
\hline Dyslipidemia & $\begin{array}{l}1.625(1.087- \\
2.429)\end{array}$ & 0.018 & & \\
\hline Initial shockable rhythm & $\begin{array}{l}4.042(3.033- \\
5.386)\end{array}$ & $<0.001$ & $\begin{array}{l}4.06(2.803- \\
5.882)\end{array}$ & $<.001$ \\
\hline Witnessed by bystander & $\begin{array}{l}2.061(1.641- \\
2.588)\end{array}$ & $<.001$ & $\begin{array}{l}1.708(1.283- \\
2.275)\end{array}$ & $\begin{array}{l}< \\
0.001\end{array}$ \\
\hline Bystander CPR & $\begin{array}{l}1.496(1.224- \\
1.829)\end{array}$ & $<.001$ & $\begin{array}{l}1.387(1.085- \\
1.774)\end{array}$ & 0.009 \\
\hline Defibrillation number & $\begin{array}{l}0.856(0.816- \\
0.899)\end{array}$ & $\begin{array}{l}< \\
0.001\end{array}$ & $\begin{array}{l}0.805(0.756- \\
0.856)\end{array}$ & $<.001$ \\
\hline $\begin{array}{l}\text { Drug administration by EMS } \\
\text { personnel }\end{array}$ & $\begin{array}{l}0.482(0.37- \\
0.629)\end{array}$ & $<.001$ & $\begin{array}{l}0.571(0.412- \\
0.79)\end{array}$ & $<.001$ \\
\hline Prehospital advanced airway & $\begin{array}{l}0.833(0.58- \\
1.197)\end{array}$ & 0.323 & & \\
\hline \multicolumn{5}{|l|}{ Time variables } \\
\hline $\begin{array}{l}\text { Arrest time to } 1 \text { st defibrillation, } \\
\text { minutes }\end{array}$ & $\begin{array}{l}0.997(0.994- \\
1.001)\end{array}$ & 0.164 & & \\
\hline
\end{tabular}

*Covariates were adjusted for in the multivariable analyses included sex, age, prehospital initial shockable rhythm, bystander CPR, witnessed by a bystander, number of defibrillation attempts, drug administration by EMS personnel, prehospital advanced airway and time interval (arrest time, response time, scene time and transport time).

$\mathrm{Cl}=$ confidence interval; $\mathrm{CPR}=$ cardiopulmonary resuscitation; $\mathrm{EMS}=$ emergency medical services; OR = odds ratio; $\mathrm{ROSC}=$ return of spontaneous circulation 


\begin{tabular}{|c|c|c|c|c|}
\hline \multirow{2}{*}{$\begin{array}{l}\text { Variables } \\
\text { Response time, minutes }\end{array}$} & \multicolumn{2}{|l|}{$\begin{array}{l}\text { Univariate } \\
\text { regression analysis }\end{array}$} & \multicolumn{2}{|c|}{$\begin{array}{l}\text { Multivariable } \\
\text { regression analysis }\end{array}$} \\
\hline & $\begin{array}{l}0.956(0.934- \\
0.979)\end{array}$ & $<0.001$ & $\begin{array}{l}0.946(0.92- \\
0.973)\end{array}$ & $<.001$ \\
\hline Scene time, minutes & $\begin{array}{l}0.946(0.93- \\
0.961)\end{array}$ & $<.001$ & & \\
\hline Transport time, minutes & $1.01(1.005-1016)$ & $<0.001$ & & \\
\hline \multicolumn{5}{|c|}{$\begin{array}{l}\text { *Covariates were adjusted for in the multivariable analyses included sex, age, prehospital initial } \\
\text { shockable rhythm, bystander CPR, witnessed by a bystander, number of defibrillation attempts, drug } \\
\text { administration by EMS personnel, prehospital advanced airway and time interval (arrest time, } \\
\text { response time, scene time and transport time). }\end{array}$} \\
\hline \multicolumn{5}{|c|}{$\begin{array}{l}\mathrm{Cl}=\text { confidence interval; } \mathrm{CPR}=\text { cardiopulmonary resuscitation; } \mathrm{EMS}=\text { emergency medical services; } \mathrm{OR} \\
=\text { odds ratio; } \mathrm{ROSC}=\text { return of spontaneous circulation }\end{array}$} \\
\hline
\end{tabular}

Multivariable logistic regression analysis was performed to predict prehospital ROSC. The OR of older age for predicting prehospital ROSC 0.971 (Cl: 0.964-0.979, p < 0.001) (Table 2). Bystander CPR, shockable rhythm, and witnessed arrest were significantly associated with prehospital ROSC (OR: 1.387, 4.06 and 1.708 , respectively). An increased number of defibrillations was significantly associated less prehospital ROSC (OR: $0.805, \mathrm{Cl}: 0.756-0.856, \mathrm{p}<0.001)$. Multivariable logistic regression analysis was performed to predict good neurological outcome at hospital discharge and was similar to the result of predicting prehospital ROSC. Age was significantly associated with a poorer neurologic outcome (OR: $0.963 \mathrm{Cl}$ : 0.955-0.971, $\mathrm{p}<0.001$ ) (Additional table). An increased number of defibrillations was significantly associated with a poorer neurological outcome (OR: 0.858, Cl: $0.803-0.916, p<0.001)$.

\section{Discussion}

This study found that the cumulative prehospital ROSC rates and good neurologic outcome from first defibrillation to the sixth defibrillation were $43 \%, 68 \%, 81 \%, 90 \%, 95 \%, 98 \%$ and $42 \%, 66 \%, 81 \%, 90 \%, 95 \%$, $98 \%$, respectively. ROSC rates decreased as the number of defibrillation attempts at the prehospital stage increased from the first to the sixth. $16 \%, 11 \%, 7 \%, 5 \%, 3 \%$ and $1 \%$, respectively. More than $95 \%$ of prehospital ROSC were achieved within five defibrillation attempts, and more than five were associated with a sharp decline in the prehospital ROSC rate in OHCA patients. Results from a subgroup of patients that received the initial defibrillation in less than 10 minutes, which is the median time from cardiac arrest to first defibrillation, were similar to the main results.

Currently there is no consensus for the number of prehospital defibrillation attempts prior to hospital transfer when shockable rhythm is observed. Since the prehospital ROSC rate is reduced after five or more defibrillation attempts, this study may provide a basis for a standardization of the number of 
defibrillation attempts before transfer to hospital. If prehospital ROSC is not achieved, even after four or five defibrillation in the prehospital stage, it is likely that specialized treatment at the hospital, such as extracorporeal membrane oxygenation CPR, could be considered. To the best of our knowledge, the cumulative prehospital ROSC rates based on the number of defibrillation attempts using nationwide prospective registry data, especially advanced in recent cardiac arrest resuscitation has not been previously reported.

Early defibrillation is vital for the survival of OHCA cases $[18,19]$. Defibrillation and chest compression effectiveness decreases rapidly, and survival rates are reduced when the collapse time is $>10$ minutes [20]. Several studies have shown that increasing the number of defibrillations in OHCA patients is associated with poor prognosis $[20,21]$. Hagihara et. al. investigated which defibrillator type is associated with a better prognosis when the number of defibrillations increased, and reported that biphasic defibrillators were associated with a better prognosis when compared to monophasic defibrillators [20]. There was no analysis of the ideal number of defibrillations at the prehospital stage. One study conducted in Japan reported a cutoff point between two and three defibrillations, whereby the chance survival after one-month was significantly reduced when more than three defibrillation were used [21]. In that study, the primary endpoint was one-month survival, and the cumulative outcome rate according to the number of defibrillations were not analyzed. Signal detection analysis (determining the largest $\chi 2$ value at a certain cut-off point) was used to estimate the ideal number of prehospital defibrillations. Since only patients with witnessed cardiac arrests were included, the number of patients used in the final analysis was limited to $4.2 \%$ of the total cohort. There is a difference in finding the ideal number of defibrillations that achieve more than $95 \%$ of ROSC in our study. Our study demonstrated that increasing numbers of defibrillations were significantly associated with reduced prehospital ROSC and poorer neurologic outcome. When the time from cardiac arrest to the initial defibrillation was too long, defibrillation was less effective. Therefore, we performed subgroup analysis using a patient cohort that underwent the first defibrillation within 10 minutes, and resulted in similar outcomes. An alternative to conventional CPR employs extracorporeal membrane oxygenation CPR and it has been reported to be effective for patients who do not fit the criteria for conventional CPR [22-24]. Patients exhibiting cardiac arrest who are refractory to prehospital defibrillation may be considered for further treatment by promptly transferring them to specialized centers. It becomes difficult to decide how many times to perform defibrillation in the prehospital stage, but it seems that this study can be a starting point for further research regarding the optimal number of defibrillation attempts.

There are several limitations to this study. Our report was driven by prospectively collected registry data, but as it was not created for the purpose of the number or time of defibrillations, 165 cases (7\%) were excluded from the analysis due to missing defibrillation related information. This study did not consider defibrillation conducted by bystander. Defibrillation performed by a bystander can also affect the prehospital ROSC. However, out of all patients, only 40 cases of defibrillation were performed by a bystander, so the main result is unlikely to be affected. Another limitation is the type of defibrillator in each EMS, whether it is automated external defibrillator, monophasic or biphasic, and the energy level will also affect the results, but that information could not be obtained from this registry. However, in Korea, it 
is known that biphasic defibrillators are more commonly used than monophasic. Biphasic defibrillators are superior to monophasic in terms of short and long term prognosis of patients with OHCA [20]. We did not address target temperature management or coronary angiography at the hospital stage as adjustment, which may affect patient outcomes. However, since our study's primary endpoint was prehospital ROSC, we do not believe it would have affected the main results. Data regarding cardioactive (epinephrine) and antiarrhythmic agents (amiodarone) were not included in the analysis. However, the frequency of use for was only 57 and 20 cases, respectively, therefore, we do not believe it would have affected the main results.

\section{Conclusion}

In our study, an increased number of defibrillation attempts at the prehospital stage was significantly associated with reduced ROSC. The cumulative ROSC rates from the initial defibrillation to the fifth defibrillation were $43 \%, 68 \%, 81 \%, 90 \%$, and $95 \%$, respectively. For patients with refractory ventricular fibrillation OHCA, the results of our study have provided a basis for the standardization of the number of defibrillations prior to hospital transfer to increase the probability of receiving rescue therapy such as extracorporeal CPR.

\section{Abbreviations}

Cl: confidence interval; CPC: Cerebral Performance Category; CPR: cardiopulmonary resuscitation; ED: emergency departments; EMS: emergency medical services; IQR: interquartile range; KoCARC: Korean Cardiac Arrest Research Consortium; OHCA: out-of-hospital cardiac arrest; OR: odds ratio; pVT: pulseless ventricular tachycardia; ROSC: return of spontaneous circulation; VF:ventricular fibrillation

\section{Declarations}

\section{Acknowledgements}

This work was supported by the research fund of Hanyang University (HY-2018).

\section{Authors' contributions}

Won Young Kim had full access to all of the data in the study and takes responsibility for the integrity of the data and the accuracy of the data analysis. Study concept and design: Won Young Kim, Tae Ho Lim and Sung Oh Hwang. Acquisition, analysis, or interpretation of data: Youn-Jung Kim, Kap Su Han and You Hwan Jo. Drafting of the manuscript: Byuk Sung Ko, Won Young Kim and Hyunggoo Kan. Critical revision of the manuscript for important intellectual content: You Hwan Jo and Jonghwan Shin. Statistical analysis: Incheol Park and Hyunggoo Kang. Study supervision: Sung Oh Hwang, Tae Ho Lim and Won Young Kim.

\section{Funding}


This work did not receive public or private funding.

\section{Availability of data and materials}

The datasets used and/or analyzed during the current study are available from the corresponding author on reasonable request.

\section{Ethics approval}

The KoCARC data collection protocol was reviewed and approved by the Institutional Review Board of each participating hospital. The KoCARC Registry was registered at Clinicaltrials.gov (Identifier NCT03222999).

\section{Consent for publication}

Not applicable

\section{Competing interests}

The authors have no conflicts of interest to report.

\section{Author details}

${ }^{1}$ Department of Emergency Medicine, College of Medicine, Hanyang University, Seoul, Republic of Korea.

${ }^{2}$ Department of Emergency Medicine, University of Ulsan College of Medicine, Asan Medical Center, Seoul, Republic of Korea. ${ }^{3}$ Department of Emergency Medicine, Korea University, College of Medicine, Seoul, Republic of Korea. ${ }^{4}$ Department of Emergency Medicine, Seoul National University Bundang Hospital, Seongnam-si, Gyeonggi-do, Republic of Korea. ${ }^{5}$ Department of Emergency Medicine, Seoul National University College of Medicine, Seoul Metropolitan Government Seoul National University Boramae Medical Center, Seoul, Republic of Korea. ${ }^{6}$ Department of emergency medicine, Yonsei University College of Medicine, Seoul, Republic of Korea. ${ }^{7}$ Department of Emergency Medicine, Yonsei University Wonju College of Medicine, Wonju, Republic of Korea.

\section{References}

1. McNally B, Robb R, Mehta M, Vellano K, Valderrama AL, Yoon PW, et al. Out-of-hospital cardiac arrest surveillance-cardiac arrest registry to enhance survival (CARES), United States, October 1, 2005December 31, 2010. Morb Mortal Wkly Rep Surveill Summ. JSTOR; 2011;60:1-19.

2. Daya MR, Schmicker RH, Zive DM, Rea TD, Nichol G, Buick JE, et al. Out-of-hospital cardiac arrest survival improving over time: results from the Resuscitation Outcomes Consortium (ROC). Resuscitation. Elsevier; 2015;91:108-15.

3. Wissenberg M, Lippert FK, Folke F, Weeke P, Hansen CM, Christensen EF, et al. Association of national initiatives to improve cardiac arrest management with rates of bystander intervention and patient 
survival after out-of-hospital cardiac arrest. Jama. American Medical Association; 2013;310:137784.

4. Bougouin W, Lamhaut L, Marijon E, Jost D, Dumas F, Deye N, et al. Characteristics and prognosis of sudden cardiac death in Greater Paris. Intensive Care Med. Springer; 2014;40:846-54.

5. Meaney PA, Nadkarni VM, Kern KB, Indik JH, Halperin HR, Berg RA. Rhythms and outcomes of adult in-hospital cardiac arrest. Crit Care Med. LWW; 2010;38:101-8.

6. Kang J-Y, Kim Y-J, Shin YJ, Huh JW, Hong S-B, Kim WY. Association between time to defibrillation and neurologic outcome in patients with in-hospital cardiac arrest. Am J Med Sci. Elsevier; 2019;358:143-8.

7. De Regge M, Monsieurs KG, Vandewoude K, Calle PA. Should we use automated external defibrillators in hospital wards? Acta Clin Belg. Taylor \& Francis; 2012;67:241-5.

8. Ryoo SM, Lee DH, Lee BK, Youn CS, Kim Y-J, Kim SJ, et al. Prognostic Factors for Re-Arrest with Shockable Rhythm during Target Temperature Management in Out-Of-Hospital Shockable Cardiac Arrest Patients. J Clin Med. Multidisciplinary Digital Publishing Institute; 2019;8:1360.

9. Nordseth T, Olasveengen TM, Kvaløy JT, Wik L, Steen PA, Skogvoll E. Dynamic effects of adrenaline (epinephrine) in out-of-hospital cardiac arrest with initial pulseless electrical activity (PEA). Resuscitation. Elsevier; 2012;83:946-52.

10. Nolan JP, Hazinski MF, Aickin R, Bhanji F, Billi JE, Callaway CW, et al. Part 1: executive summary: 2015 international consensus on cardiopulmonary resuscitation and emergency cardiovascular care science with treatment recommendations. Resuscitation. Elsevier; 2015;95:e1-31.

11. Valenzuela TD, Roe DJ, Cretin S, Spaite DW, Larsen MP. Estimating effectiveness of cardiac arrest interventions: a logistic regression survival model. Circulation. Am Heart Assoc; 1997;96:3308-13.

12. Larsen MP, Eisenberg MS, Cummins RO, Hallstrom AP. Predicting survival from out-of-hospital cardiac arrest: a graphic model. Ann Emerg Med. Elsevier; 1993;22:1652-8.

13. Koster RW, Walker RG, Chapman FW. Recurrent ventricular fibrillation during advanced life support care of patients with prehospital cardiac arrest. Resuscitation. Elsevier; 2008;78:252-7.

14. Kim JY, Hwang SO, Do Shin S, Yang HJ, Chung SP, Lee SW, et al. Korean cardiac arrest research consortium (KoCARC): rationale, development, and implementation. Clin Exp Emerg Med. The Korean Society of Emergency Medicine; 2018;5:165.

15. Yoon JC, Kim Y-J, Ahn S, Jin Y-H, Lee S-W, Song KJ, et al. Factors for modifying the termination of resuscitation rule in out-of-hospital cardiac arrest. Am Heart J. Elsevier; 2019;213:73-80.

16. Shin S Do, Hock Ong ME, Tanaka H, Ma MH-M, Nishiuchi T, Alsakaf O, et al. Comparison of emergency medical services systems across Pan-Asian countries: a Web-based survey. Prehospital Emerg care. Taylor \& Francis; 2012;16:477-96.

17. Jacobs I, Nadkarni V, Outcomes ITF on CA and CR, PARTICIPANTS C, Bahr J, Berg RA, et al. Cardiac arrest and cardiopulmonary resuscitation outcome reports: update and simplification of the Utstein templates for resuscitation registries: a statement for healthcare professionals from a task force of the International Liaison Committee on Resusci. Circulation. Am Heart Assoc; 2004;110:3385-97. 
18. Stiell IG, Wells GA, Field B, Spaite DW, Nesbitt LP, De Maio VJ, et al. Advanced cardiac life support in out-of-hospital cardiac arrest. N Engl J Med. Mass Medical Soc; 2004;351:647-56.

19. Cummins RO, Ornato JP, Thies WH, Pepe PE. Improving survival from sudden cardiac arrest: the" chain of survival" concept. A statement for health professionals from the Advanced Cardiac Life Support Subcommittee and the Emergency Cardiac Care Committee, American Heart Association. Circulation. Am Heart Assoc; 1991;83:1832-47.

20. Hagihara A, Onozuka D, Ono J, Nagata T, Hasegawa M. Interaction of defibrillation waveform with the time to defibrillation or the number of defibrillation attempts on survival from out-of-hospital cardiac arrest. Resuscitation. Elsevier; 2018;122:54-60.

21. Hasegawa $M, A$, Abe T, Nagata T, Onozuka D, Hagihara A. The number of prehospital defibrillation shocks and 1-month survival in patients with out-of-hospital cardiac arrest. Scand J Trauma Resusc Emerg Med. Springer; 2015;23:34.

22. Nagao K, Hayashi N, Kanmatsuse K, Arima K, Ohtsuki J, Kikushima K, et al. Cardiopulmonary cerebral resuscitation using emergency cardiopulmonary bypass, coronary reperfusion therapy and mild hypothermia in patients with cardiac arrest outside the hospital. J Am Coll Cardiol. Journal of the American College of Cardiology; 2000;36:776-83.

23. Chen Y-S, Lin J-W, Yu H-Y, Ko W-J, Jerng J-S, Chang W-T, et al. Cardiopulmonary resuscitation with assisted extracorporeal life-support versus conventional cardiopulmonary resuscitation in adults with in-hospital cardiac arrest: an observational study and propensity analysis. Lancet. Elsevier; 2008;372:554-61.

24. Kagawa E, Inoue I, Kawagoe T, Ishihara M, Shimatani Y, Kurisu S, et al. Assessment of outcomes and differences between in-and out-of-hospital cardiac arrest patients treated with cardiopulmonary resuscitation using extracorporeal life support. Resuscitation. Elsevier; 2010;81:968-73.

\section{Figures}




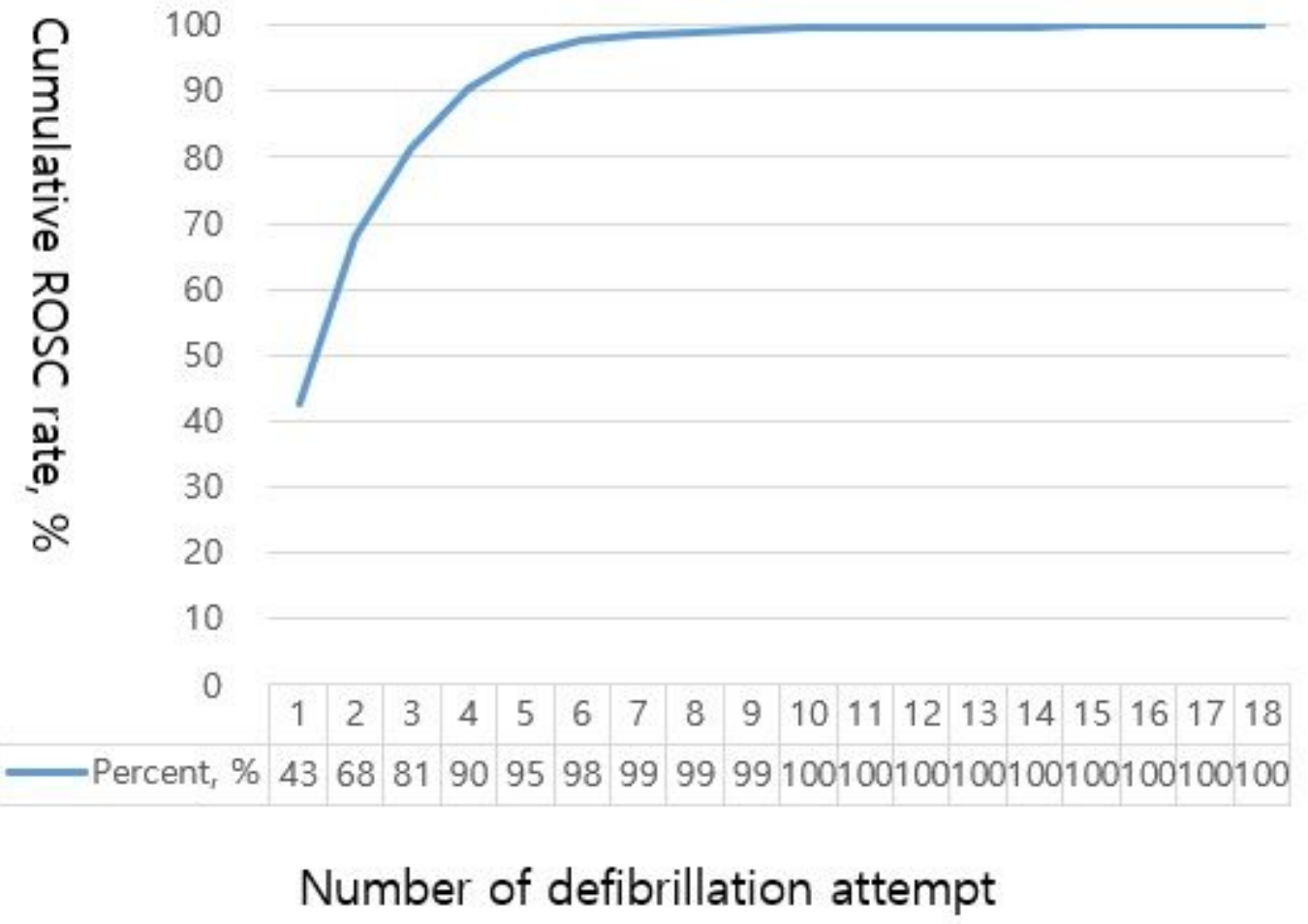

Figure 1

Cumulative ROSC rate according to the number of defibrillation attempts. ROSC, return of spontaneous circulation. 


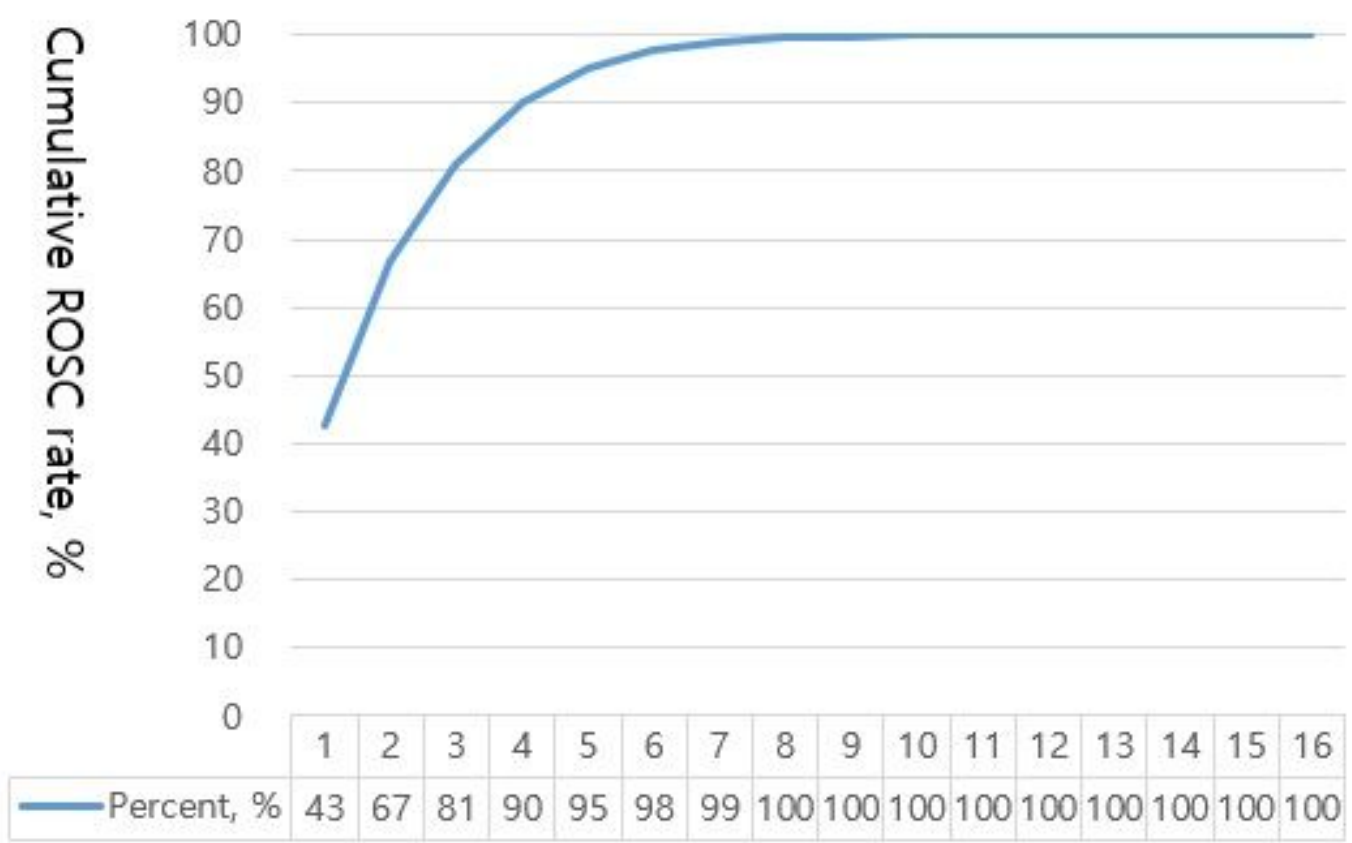

\section{Number of defibrillation attempt}

\section{Figure 2}

Cumulative ROSC rate according to the number of defibrillation attempts in patients that received the initial defibrillation within 10 minutes. ROSC, return of spontaneous circulation. 


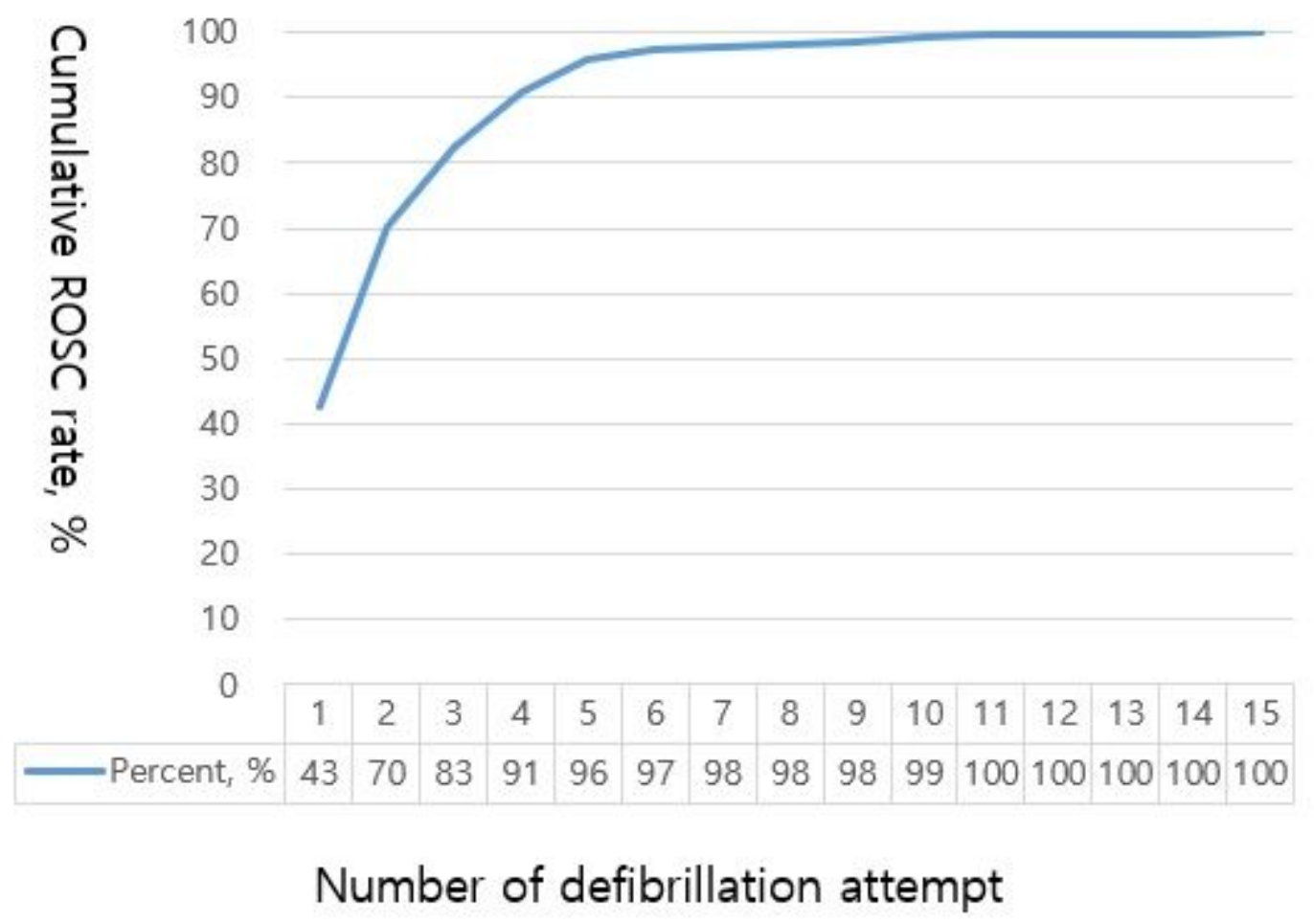

Figure 3

Cumulative ROSC rate according to the number of defibrillation attempts in patients that received the initial defibrillation after more than 10 minutes. ROSC, return of spontaneous circulation.

\section{Supplementary Files}

This is a list of supplementary files associated with this preprint. Click to download.

- defibaddtableCC20201105.docx

- kocarcdefibsupeFig20200827.pptx 